\title{
Desterro, \\ legitimidade e \\ distribuição de \\ poder: o panorama \\ político entre os \\ reinados de Juan II e \\ Enrique IV de \\ Castela (1445-1454)
}

\section{Gabriel Soledade Pereira Lima*}

DOI: 10.11606/issn.2318-8855.v10i2p670-695

Resumo: Na Batalha de Olmedo (1445), duas redes políticas - os Infantes de Aragão e os aliados do valido Álvaro de Luna - se enfrentaram, decidindo o futuro da dinâmica política do reino de Castela. Após a derrota dos Infantes e seus aliados, a disponibilidade de senhorios no reino mobilizou grande parte da nobreza em uma disputa que envolveria derrotados, vencedores, e novos agentes políticos em ascensão. Este trabalho pretende abordar essa disputa, por meio de uma seleção de crônicas que tratam do período, do diálogo com a historiografia e da análise do papel de Juan II e de Enrique IV como distribuidor de poder e legitimidade.

Palavras-chaves: Castela Medieval, Juan II, Enrique IV, Álvaro de Luna, Redes de poder.

* Graduando em História pela Universidade de Brasília (UnB) e colaborador do Programa de Estudos Medievais (PEM)

- UnB. E-mail para contato: gabriel.soledade@gmail.com 


\section{O Poder na Idade Média}

Desterro, legitimidade e distribuição de poder

\section{Introdução}

A Batalha de Olmedo de 1445 foi um marco de mudança política no reino de Castela. Os anos seguintes seriam marcados pela ascensão de personagens emblemáticos dos reinados posteriores. Mobilizando grande parte da nobreza, duas redes políticas se enfrentaram em Olmedo: os Infantes de Aragão, herdeiros do projeto político de Fernando de Antequera, e os aliados do condestável Álvaro de Luna, uma figura política expressiva durante o reinado de Juan II. A vitória do lado em que lutavam Juan II e Álvaro de Luna criou condições para a ascensão política de diversas figuras que souberam se aproveitar do panorama político.

É possível perceber, nos anos finais do reinado de Juan II (1406-1454), uma dinâmica política que girava ao redor dos senhorios declarados "vagos" pelo monarca após Olmedo. Analisando essa dinâmica, pode-se chegar a conclusões acerca de aspectos mais amplos que excedem a particularidade do recorte: a lógica política do período, a natureza do poder monárquico e sua interação com redes de poder com as quais estava imbricado. É, portanto, através do contexto de 1445-1454 que se pretende abordar o poder monárquico, seu papel e sua interação com redes políticas.

A mudança política que se operou nos nove anos entre a batalha de Olmedo (1445) e o início do reinado de Enrique IV de Castela (1454) não pode ser explicada apenas pela ascensão dos partidários do condestável Álvaro de Luna. O consenso historiográfico a respeito do período posiciona as figuras de Álvaro de Luna e dos Infantes de Aragão como representantes de projetos políticos e de grupos nobiliárquicos específicos: a pequena e a grande nobreza, respectivamente. No entanto, dividir a nobreza, desconsiderando os laços de poder e as redes às quais os indivíduos pertencem, pode levar a uma esquematização do cenário político do 


\section{O Poder na Idade Média}

Gabriel Soledade Pereira Lima

período. Da mesma forma, apresentar os enfrentamentos do século XV como resultados de uma luta polarizada entre nobreza e monarquia (SUÁREZ FERNANDEZ, 1970, p. 520), ou reduzir a explicação do período à forma como os validos supostamente dominavam os monarcas e afrontavam a nobreza (MANZANO MORENO, 2010, p. 633), é, pelo menos no caso de 1445-1454, desconsiderar alguns aspectos importantes para compreender a lógica política do período. A multiplicidade de partidos e de agentes políticos aponta para uma pluralidade de interesses que se utilizam de diversas estratégias, como a dinâmica dos desterros, para seu fortalecimento.

Para fundamentar o estudo, foram utilizadas quatro crônicas que abordam o período já destacado: a Crónica de Juan II, de Fernán Pérez de Guzmán; a Crónica del Halconero de Juan II, de Pedro Carrillo de Huete; a Crónica de Enrique IV, de Alonso de Palencia; e a Crónica de D. Álvaro de Luna, de Josef Miguel de Flores. As crônicas foram produzidas durante os reinados de Juan II e Enrique IV, com variações de datação a depender do protagonista e do autor de cada uma. Todos os autores estiveram envolvidos em alguma medida com a dinâmica de corte e a política do reino. Fernán Pérez de Guzmán tinha conexões com as grandes famílias, Pedro Carrillo de Huete era halconero de Juan II e membro de sua corte. Todas as crônicas e seus autores estão conectados, em diferentes medidas, ao contexto cortesão e político de Castela. As fontes, portanto, estão diretamente relacionadas com os arranjos de poder e conflitos que serão abordados adiante. A disputa entre as crônicas - frequentemente dissonantes em suas narrativas - é mais um fator que remete aos grupos em competição durante os reinados, que também competiam entre si no plano da narrativa. 


\section{O Poder na Idade Média}

\section{Desterro, legitimidade e distribuição de poder}

Juan II, embora colocado em segundo plano pela historiografia, assume papel destacado nas crônicas: o monarca se posiciona como elemento central na distribuição de riqueza e no compartilhamento do poder. O papel do monarca como propiciador de legitimidade é central e condizente com as expectativas da sociedade acerca do poder régio, pois o coloca como elo entre redes políticas que dependem dele para sua expansão. Pode-se perceber que a grande maioria das concessões de territórios, vilas, castelos, títulos, direitos ou ofícios régios são operadas por intermédio do rei. De fato, mesmo que algumas narrativas ressaltem aquilo que consideram a característica negativa do monarca - de total submissão ao seu valido, portanto, seu fantoche - ainda assim, reconhecem a sua relevância como intermediário, embora passivo, nas alianças e disputas políticas das redes de poder.

\section{I.A disputa narrativa nas crônicas}

Com base nas crônicas produzidas sobre o período em questão, é perceptível uma disputa de narrativas e de representação histórica na maneira como se retrata o reinado de Juan II. É justamente através da pluralidade narrativa das crônicas, da tipologia da documentação, e da inclusão de narrativas normalmente desconsideradas pela historiografia, que propomos algumas reflexões.

Produzida dentro do ambiente cortesão, a crônica tem o objetivo de construir uma narrativa específica acerca de certos acontecimentos que promovem a figura principal tratada pela fonte. Dessa maneira, as crônicas caracterizam seus personagens sob vários pontos de vista, essencialmente políticos e alinhados à agenda do grupo que as encomenda. No caso das crônicas utilizadas nesta pesquisa, a maneira como se trata o reinado de Juan II e as disputas políticas ocorridas evidencia uma disputa narrativa e de representação histórica. 


\section{O Poder na Idade Média}

Gabriel Soledade Pereira Lima

Comparando as crônicas estudadas, a Crónica de Juan II, a Crónica del Halconero de Juan II, a Crónica de Enrique IV, e a Crónica de D. Álvaro de Luna, é possível situá-las, através de suas estratégias narrativas, em posições políticas muito bem definidas. Considerando a autoria distinta de cada uma das narrativas (GÓMEZ REDONDO, 2004, p. 199-201), é possível associá-las a agendas políticas dos grupos em conflito durante o período mais amplo do século XV castelhano. Entretanto, ainda que tal disputa seja explícita nas fontes, a historiografia raramente a reconhece como elemento importante da análise. Há uma tendência a escolher uma das crônicas como mais válida ou verídica, desmerecendo, ou até mesmo desconsiderando, as demais.

A Crónica de Juan II, como já referido, dá grande ênfase ao monarca e ao confisco dos senhorios dos desterrados, apresentando a ação do rei como alinhada às expectativas modelares de um monarca justo e magnânimo. Entretanto, a crônica compartilha algumas críticas que são comuns a quase todas as outras narrativas, principalmente no que diz respeito ao controle de Álvaro de Luna sobre a figura régia. Mesmo assim, há um esforço para caracterizar os eventos sob uma perspectiva que podemos considerar favorável a Juan II e, em certa medida, a seu filho, Enrique. A Crónica del Halconero de Juan II também pode ser caracterizada dessa maneira, considerando-se ter sido produzida na corte, apesar de ser marcadamente crítica à atuação Álvaro de Luna.

A Crónica de Enrique IV, mais agressiva em sua narrativa, revela muito bem a disputa pelo plano da memória ocorrida no período. Pessimista em relação aos reinados de Juan II e de Enrique IV, a crônica discorre em grande medida sobre o domínio dos validos sobre os monarcas, sobre a fraqueza dos reis, e sobre a imagem de um século de crise. Pode-se perceber que essa estruturação narrativa da fonte mereceu especial atenção e crédito da historiografia. 


\section{O Poder na Idade Média}

Desterro, legitimidade e distribuição de poder

A Crónica de D. Álvaro de Luna, alinhada à figura do condestável, busca caracterizá-lo da melhor maneira, como um bom cavaleiro a serviço de seu rei. Exaltando D. Álvaro como um senhor modelar, e justificando suas ações políticas através do discurso do bem comum, do bem do reino, a crônica relata os acontecimentos aqui mencionados de uma maneira distinta das outras narrativas.

Há de se compreender que nenhuma dessas crônicas pode ser tomada como verdade absoluta. É preciso reconhecer, através de sua tipologia documental, o valor e as limitações dessas narrativas, para que possam ser utilizadas na produção de um trabalho historiográfico. Levar em consideração diferentes narrativas, especialmente as que não foram privilegiadas na construção do discurso historiográfico, se mostra produtivo para caracterizar o século XV sob uma ótica distinta. No caso da Crónica de Juan II, a dinâmica dos desterros e a imagem de um monarca que concede legitimidade e senhorios são aspectos pouco trabalhados pela historiografia que podem contribuir para adensar a interpretação do período após Olmedo. Entendê-lo sob uma ótica que evidencia as múltiplas redes políticas, aspecto evidente na própria documentação, parece ser um caminho promissor.

\section{O desterro e a dinâmica política de 1445-1454}

Reintroduzindo sujeitos que foram marginalizados da narrativa historiográfica entre 1445 e 1454, é possível perceber um contexto político muito menos linear e mais complexo, com uma pluralidade de agentes competindo pelo poder no território castelhano. Os grupos dificilmente obedecem a classificações tão homogeneizantes como as "ligas de nobres" apresentadas pela historiografia. No entanto, os sujeitos comumente considerados centrais na narrativa historiográfica, ainda que não sejam 


\section{O Poder na Idade Média}

Gabriel Soledade Pereira Lima

suficientes para definir o período, não deixam de ser relevantes nesse panorama político.

Homens influentes e poderosos perderam muito do que possuíam no reino de Castela depois da Batalha de Olmedo: é o caso do Almirante Mayor de Castela, Fadrique Enríquez, de Alonso Pimentel, conde de Benavente, e outros que se posicionaram a favor dos Infantes de Aragão na batalha. Nos anos seguintes, a tomada de castelos e vilas pertencentes aos nobres "desterrados" e a reestruturação política posterior ao conflito mobilizaram a atenção de Juan II e de seus partidários, ditando em boa medida os rumos internos da política do reino de Castela.

A Crónica de Juan II, entre os anos de 1445 e 1454, descreve minuciosamente a dinâmica política em torno dos senhorios dos "desterrados". Ainda que exilados, esses nobres continuam a exercer pressão política no reino, pelo amparo das redes políticas que os sustentavam externamente. Forma-se uma complexa situação, na medida em que nobres exilados buscam a reintegração de seus senhorios e, quando possível, o perdão régio, e, ao mesmo tempo, em que outros nobres veem o desterro dos vencidos como uma oportunidade de ascensão.

Ainda que tenham sido perdoados logo no ano de 1445 , colaborando com a monarquia durante esse tempo - segundo a Crónica de Juan II - o Almirante e o conde de Benavente permaneceram, salvo em alguns momentos pontuais, exilados do reino de Castela, até o reinado de Enrique IV (PÉREZ DE GUZMÁN, 1779, p. 500). Em 1448, D. Alonso de Fonseca, Álvaro de Luna e Juan Pacheco teriam, segundo a crônica, orquestrado a prisão de muitos nobres notáveis do reino, entre eles o conde de Benavente e o Almirante (PÉREZ DE GUZMÁN, 1779, p. 529). Esse fato reiniciaria as hostilidades, compelindo esses nobres à fuga para territórios protegidos por suas 


\section{O Poder na Idade Média}

\section{Desterro, legitimidade e distribuição de poder}

redes políticas. Dessa forma, continuam a exercer pressão política mesmo enquanto "desterrados", procurando, também, manter seus senhorios castelhanos. Um desses casos é descrito na crônica:

O rei, tendo cercada a vila de Benavente [...] como para tomar a fortaleza depois se ela não quisesse se entregar. [...] Os de Benavente recorreram logo ao conde, o qual, vendo que não podia socorrê-los [...], disse que se entregassem ao rei: o que assim se fez, pois, logo vista a resposta do Conde, foi logo entregue [...] ao Rei: e aposentado nela, mandou logo que se combatesse a fortaleza [...] e como a fortaleza é muito forte, e como nela estavam muitos homens de infantaria criados do Conde e de Pedro de Quiñones, que ali tinham se acolhido, defenderam-se muito bem, e não fugiram do combate (PÉREZ DE GUZMÁN, 1779, p. 538).

O conflito no vilarejo e fortaleza de Benavente não é caso único. Além do conde, o próprio Almirante articulou politicamente a ajuda militar do reino de Aragão contra as tropas do monarca castelhano. As incursões de mouros em 1446 e 1447, ainda que não estejam assim associadas nas crônicas, podem, também, ser relacionadas a esse panorama político (PÉREZ DE GUZMÁN, 1779, p. 521 e 526). Além dos dois nobres, o conde de Castro, Pedro e Suero de Quiñones, Rodrigo Manrique, entre outros, perdoados após Olmedo, também estariam envolvidos nas disputas políticas ocorridas entre 1445 e 1454. O conde de Castro, posteriormente associado ao grupo do príncipe Enrique, teria sido outro alvo das prisões de 1448 e que, juntamente com o Almirante, Juan de Tovar, e outros, criaria conflitos em território castelhano articulando-se com os reinos de Navarra e Aragão. É importante ressaltar que os senhorios desses nobres não se restringiam ao reino de Castela. $O$ conde de

\footnotetext{
${ }^{1}$ No original: "El Rey, teniendo cercada esta villa de Benavente [...] como para tomar después la fortaleza si no se quisiese entregar. [...] los de Benavente enbiáron luego al conde, el qual veyendo que no los podía socorrer [...], enbióles mandar que se entregasen al Rey: lo qual así se hizo, que luego vista la respuesta del Conde, fue luego entregada [...] al Rey: é aposentado en ella, mandó luego que se conbatiese la fortaleza [...] é como la fortaleza es asaz fuerte, é como en ella estaban muchos hombres de pie criados del Conde é de Pedro de Quiñónes, que alli habían se acogido, defendiéronse muy bien, y no se curáron del conbate." Tradução nossa.
} 


\section{O Poder na Idade Média}

Gabriel Soledade Pereira Lima

Castro e Fadrique Enríquez, por exemplo, possuíam consideráveis senhorios no reino de Aragão.

É possível observar, portanto, como a disputa política continua a ocorrer em Castela, mesmo depois da derrota dos Infantes. Os exemplos descritos até agora são apenas uma parte desses conflitos. Envolvendo uma pluralidade de personagens, as movimentações políticas nos anos finais do reinado de Juan II parecem ser significativas e diretamente associadas ao conflito de redes políticas que já ocorria antes de 1445. A suposta derrota "definitiva" dos Infantes em Olmedo (CAÑAS GALVEZ, 2010, p. 705), que os retira de cena na narrativa historiográfica, não impediu que continuassem a exercer pressão política significativa no território castelhano.

A reconfiguração política e a disponibilidade de senhorios, além de motivarem disputas, também se mostram como possibilidades de ascensão política e de prestígio. No entanto, ao contrário do que costuma defender a historiografia, essa movimentação política ocorre justamente dentro de um panorama de conflito que continua após 1445.

A mudança política em torno das dioceses, por exemplo, é especialmente movimentada, embora a historiografia não se debruce realmente sobre o tema. Bispos e monges - no caso ainda menos representados - aparecem como personagens secundários na narrativa central da historiografia que focaliza a competição pelo poder entre Álvaro de Luna, Juan Pacheco e os "Grandes". A Crónica de Juan /I menciona especialmente quatro clérigos que ascendem ao topo de uma diocese ou arquidiocese, ou que mudam de posição para uma diocese mais importante entre 1445 e 1454. O câmbio político nas dioceses parece se atribuir, principalmente, aos clérigos que lutaram ao lado de Juan II na batalha de Olmedo, 


\section{O Poder na Idade Média}

\section{Desterro, legitimidade e distribuição de poder}

como D. Alonso Carillo de Acuña, o novo arcebispo de Toledo, D. Álvaro de Osorna, novo arcebispo de Santiago, D. Alonso de Fonseca Sánles, novo bispo de Ávila, e D. Lope Barrientos, novo bispo de Cuenca.

Lope Barrientos, como Juan Pacheco, foi um dos principais conselheiros do príncipe Enrique. Participando ativamente na Batalha de Olmedo, em meio a outros bispos, Barrientos seria devidamente recompensado após 1445 por sua fidelidade ao monarca. A Crónica de Juan /l faz menção específica ao momento em que lhe é concedido o bispado de Cuenca:

[...] Como o rei o soube, mandou dizer a Don Lope de Barrientos, bispo de Ávila, que, lembrando-se dos serviços que Ihe tinha feito, queria suplicar ao Santo Padre que the provesse aquele seu bispado. O bispo respondeu que recebia o como mercê, e por isso beijava suas mãos, mas que em sua velhice não tinha vontade de ir para a Galícia. Então o rei mandou que lhe dissessem que se queria o bispado de Cuenca, que tinha Don Alvaro de Osorna, que era galego, que ele daria o Arcebispado de Santiago a este Don Alvaro, e a ele o bispado de Cuenca. O bispo entendeu isso como mercê, e assim foi provido o bispo do bispado de Cuenca... (PÉREZ DE GUZMÁN, 1779, p. 488)²

A escolha da diocese de Cuenca pode ser atribuída às raízes da família de Juan Pacheco no senhorio de Belmonte, uma vila localizada dentro dos limites da diocese. Pacheco, muito provavelmente, possuía uma rede da qual o recém apontado bispo, seu aliado político, poderia se aproveitar. Diferentemente das outras dioceses que administrou, o bispo permaneceu em Cuenca até sua morte.

\footnotetext{
${ }^{2}$ No original: "[...] como el Rey lo supo, embió á decir á Don Lope de Barrientos Obispo de Ávila, que acordándose de los servicios que le había hecho quería suplicar al Santo Padre que le proveyese de aquel su Obispado. El Obispo le respondió que gelo teñia en merced, é le besaba por ello las manos, pero que en su vejez no habia voluntad de ir á Galicia. Entonces el Rey le enbió a decir, que si quería el Obispado de Cuenca que tenia Don Alvaro de Osorna que era Gallego, que él daría el Arzobispado de Santiago á este Don Alvaro, é á él el Obispado de Cuenca. El Obispo gelo tuvo en merced, e así fue proveído el Obispo del Obispado de Cuenca..." Tradução nossa.
} 


\section{O Poder na Idade Média}

Gabriel Soledade Pereira Lima

O recém-nomeado arcebispo de Ávila, anteriormente Arquidiácono de Sánles, D. Alonso de Fonseca, também esteve envolvido na disputa política após Olmedo. De acordo com a Crónica de Juan II, o arcebispo foi um dos principais articuladores das prisões feitas em 1448, demonstrando sua proximidade política com o condestável Álvaro de Luna.

Além das dioceses, a reconfiguração política também beneficiou a outros nobres com a concessão de senhorios e títulos. Alguns deles se tornariam especialmente importantes no curto período de nove anos. Outros, ainda, continuariam a ascender politicamente durante o reinado de Enrique IV.

Iñigo López de Mendoza, anteriormente senhor das vilas de Hita e Buitrago, é elevado em 1445 aos títulos de I Conde del Real de Manzanares e I Marquês de Santillana, como recompensa por sua fidelidade na batalha de Olmedo. Mesmo que a narrativa das crônicas e da historiografia apontem sua inimizade com Álvaro de Luna, o marquês se posicionou independentemente ao lado da monarquia até os anos finais do reinado. López de Mendoza seria uma voz importante na alta nobreza castelhana, envolvido marginalmente nas disputas já descritas. O marquês de Santillana continuaria a expandir sua influência até a sua morte, em 1458, transformando sua casa em uma das mais significativas nos reinados de Enrique IV e Isabel I.

Juan Pacheco, um nobre de origem portuguesa, era neto de Juan Fernández Pacheco, português exilado após a Batalha de Aljubarrota, em 1385. Originado da baixa nobreza, Juan Pacheco obteve sucesso na corte através do príncipe Enrique e das alianças que estabeleceu. No entanto, é logo após a batalha de Olmedo que conseguiria seus maiores títulos: 


\section{O Poder na Idade Média}

\section{Desterro, legitimidade e distribuição de poder}

Na repartição dos espólios dos vencidos em Olmedo, os filhos de Alonso Téllez rivalizaram com o Condestável, pois se ele obteve o Maestrazgo de Santiago e numerosos lugares, aqueles, Juan Pacheco e Pedro Girón, se elevariam [...] à sua altura. Juan Pacheco já se havia convertido em dono de quase todo o antigo senhorio [...] mas agora aumentado com Utiel e Villanueva, El Bonillo, Lezuza e Munera [...] Em pouco tempo o Marquesado todo passaria para suas mãos (PRETEL MARIN, 1981, p. 54)3.

A ascensão de Juan Pacheco é atribuída, unanimemente, a dois fatores: a sua proximidade com o príncipe Enrique e ao apadrinhamento político de Álvaro de Luna. No caso do príncipe, a proximidade pessoal é a principal justificativa. Relativamente a Álvaro de Luna, Pacheco se mostra como um discípulo dos ideais políticos do condestável, ainda que suas fidelidades não se restringissem ao apadrinhamento político (PALENCIA, 1973, p. 52). Entretanto, a proximidade de Juan Pacheco e Álvaro de Luna é útil para o discurso das crônicas e da historiografia, na medida em que coloca os dois validos em um tipo de genealogia ideológica encabeçada pelo condestável.

Além do marquesado de Vilhena, Juan Pacheco também estaria envolvido na eleição para o Maestrazgo da Ordem de Calatrava, de seu irmão, Pedro Girón, em 1445, por intervenção do monarca, a seu pedido e do príncipe Enrique:

[...] o Príncipe Ihe suplicou, e pediu por mercê, que por Don Alonso, Mestre de Calatrava e filho do Rei de Navarra, ter the prestado desserviço, [...] mandasse aos Comendadores da Ordem de Calatrava que elegessem um pajem, que era seu privado e criado, irmão de Don Juan Pacheco, [...] que se chamava Pero Girón. O rei, para agradar ao Príncipe seu filho, e para atraí-lo à sua opinião, contrária ao Rei de Navarra, mandou que [...] elegessem por Mestre este Pero

\footnotetext{
${ }^{3}$ No original: "El reparto de los despojos de los vencidos em Olmedo, los hijos de Alonso Téllez rivalizaron con el Condestable, pues si ese obtuvo el Maestrazgo de Santiago y numerosas plazas, aquellos, Juan Pacheco y Pedro Girón, se elevarían [...] hasta su misma altura. Juan Pacheco se había convertido ya em dueño de casi todo el viejo señorío [...] pero aumentado ahora con Utiel y Villanueva, El Bonillo, Lezuza e Munera [...] En poco tiempo el Marquesado entero, pasaría a sus manos." Tradução nossa.
} 


\section{O Poder na Idade Média}

Gabriel Soledade Pereira Lima

Girón no lugar de Don Alonso filho do Rei de Navarra: o que os Comendadores logo fizeram... (PÉREZ DE GUZMÁN, 1779, p. 502) ${ }^{4}$

Pacheco se tornaria ainda mais proeminente no reinado de Enrique IV, acumulando os títulos de Duque de Escalona e Mestre da Ordem de Santiago.

É importante ressaltar que as eleições dos Maestrazgos de Santiago e Calatrava, ainda que reconhecidas por uma parcela considerável dos notáveis, sofreram grande oposição. No caso da Ordem de Santiago, o Comendador de Segura, Rodrigo Manrique, filho do falecido adelantado mayor, Pero Manrique, se proclamou Mestre da Ordem, em 1446, um ano após a eleição de Álvaro de Luna. Embora a Crónica de Juan Il se esforce para sublinhar a ilegitimidade do pleito de Rodrigo Manrique, até 1451, pelo menos, o nobre continua a se denominar Mestre de Santiago e a ter grande influência no reino (PÉREZ DE GUZMÁN, 1779, p. 524 e 551). No caso da Ordem de Calatrava, D. Alonso, filho do rei Juan II de Navarra, continuaria a se denominar como Mestre de Calatrava, após a eleição de Pedro Girón, em 1445. As ordens militares eram a principal força armada de Castela, fonte de grande riqueza (SUÁREZ FERNÁNDEZ, 1970, p. 507-508). A disputa pelo Maestrazgo, portanto, era de extrema importância para os grandes grupos que disputavam o poder naquele período.

Tanto o príncipe de Astúrias, Enrique, quanto o monarca, Juan II, acumularam senhorios depois de 1445. Seus partidários, como bem descrito no caso dos "filhos de

\footnotetext{
${ }^{4}$ No original: "[...] el Príncipe le suplicó, é pidió por merced, que pues Don Alonso Maestre de Calatrava hijo del Rey de Navarra, le había deservido, [...] mandase á los Comendadores de la Orden de Calatrava que eligiesen á un Doncel suyo, que era su privado é criado, hermano de Don Juan Pacheco, [...] que se llamaba Pero Girón. El Rey así por complacer al Príncipe su hijo, como por le atraer á su opinión contra el Rey de Navarra, mandó que [...] eligiesen por Maestra á este Pero Girón en lugar de Don Alonso hijo del Rey de Navarra: lo qual los Comendadores luego hiciéron..." Tradução nossa.
} 


\section{O Poder na Idade Média}

\section{Desterro, legitimidade e distribuição de poder}

Alonso Téllez"5, enriqueceram concomitantemente. A Crónica de Enrique IV, de Alonso de Palencia, descreve a preocupação de Álvaro de Luna com o acúmulo de senhorios do príncipe a partir da herança:

D. Alvaro, já livre de muitos receios, cuidava principalmente de se precaver contra o perigo de que o príncipe D. Enrique, filho único, destinado a herdar tantos e tão consideráveis estados, fazendo-se mais poderoso com a unidade do mando, se mostrasse menos dócil diante da certeza de obter aquele grande poderio (PALENCIA, 1978, p. 73) ${ }^{6}$.

O condestável Álvaro de Luna também experimentou a prosperidade política depois de Olmedo. Descrita como o enfrentamento entre Álvaro de Luna e os Infantes de Aragão pela historiografia, a batalha - da qual o condestável sai vitorioso - seria, paradoxalmente, o início de sua derrocada. Álvaro de Luna seria eleito Mestre de Santiago em 1445, e ganharia o título de I Duque de Trujillo, além de outros senhorios.

A historiografia atribui a "queda" de Álvaro de Luna a uma série de fatores. O primeiro seria a inimizade da nova esposa de Juan II, Isabel de Portugal, que, conquistando o monarca, teria minado a influência do condestável na esfera pessoal, apontada como a principal via de ascensão política do valido (PÉREZ DE GUZMÁN, 1779, p. 56-57). O segundo seria a queda de um dos grandes aliados do condestável: D. Pedro, Duque de Coimbra, morto em 1449, na batalha de Alfarrobeira. O novo rei de Portugal, Afonso V, se mostrou muito menos inclinado a estabelecer alianças com o condestável. As prisões de 1448, por último, fizeram com que D. Álvaro perdesse

\footnotetext{
${ }^{5}$ A expressão se refere a Juan Pacheco e seu irmão, Pedro Girón.

${ }^{6}$ No original: "Libre ya $D$. Alvaro de muchos recelos, atendía principalmente á precaverse contra el peligro de que el príncipe D. Enrique, hijo único, llamado á heredar tantos y tan considerables estados, haciéndose más poderoso con la unidad del mando, se mostrase menos dócil ante la seguridad de obtener aquel gran poderío." Tradução nossa.
} 


\section{O Poder na Idade Média}

Gabriel Soledade Pereira Lima

legitimidade, na medida em que foram consideradas injustas por grande parte dos nobres castelhanos.

É possível perceber, assim, como o panorama político castelhano, entre 1445 e 1454, é dotado de uma complexidade que excede a fórmula tripartite: o condestável e sua tirania, o príncipe que articula a nobreza contra o condestável, e Juan Pacheco, que controla o príncipe (VALDEON BARUQUE, 1968, p. 124-125). As figuras de Pacheco

e de Álvaro de Luna, ainda que importantes, não são suficientes para explicar o recorte aqui adotado. As crônicas, embora concordem em alguns aspectos com a interpretação historiográfica, revelam uma situação muito menos homogênea do cenário político.

\section{Legitimidade régia}

Considerada a pluralidade de agentes envolvidos, é necessário, também, levar em conta a importância do monarca no jogo político aqui mencionado. Frequentemente representado como um rei fraco, com seu poder usurpado pela figura de Álvaro de Luna, Juan II, ao contrário, aparece nas crônicas desempenhando funções próprias do poder régio que demonstram uma ideologia política complexa. Através das expectativas acerca do papel político régio, e da maneira como se constrói um retrato do monarca pela narrativa, é possível percebê-lo como elemento político de importância central e como esses pressupostos fundamentam sua interação com outros polos de poder. No entanto, considerar as narrativas dos grupos políticos que circundam o monarca, seja como aliados, adversários, ou ambos - e como as utilizam para legitimar o conflito - também se mostra extremamente produtivo para interpretar o período de 1445 a 1454. 


\section{O Poder na Idade Média}

\section{Desterro, legitimidade e distribuição de poder}

Ao considerar a importância do monarca e sua centralidade para as disputas entre redes políticas no âmbito castelhano, é preciso ressaltar que isso não quer dizer que se trate de um modelo político de tipo monopolista e centralizador. Ainda que seja inegável seu valor e sua especificidade insubstituível no jogo político, em nenhum momento aqui se pretende concordar com interpretações que promovem um ideal de monarquia/estado que não pertence à Idade Média. Entender o ambiente político castelhano como plural, constituído por uma multiplicidade de jurisdições concorrentes e legítimas, com motivações diversas e complexas, é a base teórica fundamental deste trabalho (COELHO, 2018, p. 133-150).

O monarca se mostra como peça de fundamental relevância na distribuição de poder no reino de Castela. Considerando a dinâmica dos desterros, referida anteriormente, a figura de Juan II esteve presente em praticamente todas as "movimentações" políticas do período, no papel de regulador ou intermediário, seja por representação direta ou indireta de sua vontade. Mesmo que suas decisões pudessem causar o desagrado de nobres, como em vários casos, tal comportamento estava completamente de acordo com as expectativas em torno do ofício régio:

A submissão dos nobres ao poder real implica também a obtenção de benefícios por eles [...]. Frente à nobreza, o rei desempenha um papel de executor da justiça distributiva que outorga grandes dons em troca da fidelidade demonstrada, devendo o rei atuar com a máxima generosidade. [...] o rei efetua uma certa atividade de estabilizador social, pois se encarrega de manter o grande em sua grandeza e o pobre em sua pobreza (NIETO SORIA, 1988, p. 170-171) ${ }^{7}$.

\footnotetext{
${ }^{7}$ No original: "La sumisión de los nobles al poder real implica también obtención de beneficios por aquellos [...]. Frente a la nobleza, el rey desempeña un papel de un ejecutor de la justicia distributiva que otorga grandes dones a cambio de la fidelidad demostrada, debiendo actuar el rey con la máxima largueza. [...] el rey efectúa una cierta actividad de estabilizador social, pues se encarga de mantener al grande en su grandeza y al pobre en su pobreza." Tradução nossa.
} 


\title{
O Poder na Idade Média
}

Gabriel Soledade Pereira Lima

Como aponta José María Monsalvo Antón, a historiografia tende a associar a nobreza a uma agenda política que enfraquece o "poder absoluto" régio, colocando o fortalecimento nobiliárquico como a antítese do fortalecimento monárquico (MONSALVO ANTÓN, 2017, p. 93-95). Mas é importante ressaltar que a dinâmica de distribuição de mercês e senhorios não apenas beneficia os nobres aliados a Juan II, como o próprio monarca. Ao integrar redes políticas e fortalecer seus aliados, o rei também se fortalece, simultaneamente. A partir da concepção política de Diego de Valera, um intelectual e cortesão castelhano do século XV, Nieto Soria elabora esta dupla relação:

\begin{abstract}
A nobreza contribui ao prestigiar um rei, pois ele deve sempre se preocupar de estar bem rodeado de grandes senhores. Quanto mais nobres tenha um príncipe a seu serviço, tanto mais poderoso poderá ser considerado. Se deverá outorgar a esses nobres quantas mais dignidades e poderes for possível, pois a glória do soberano será maior quanto maior é o poder de seus grandes (NIETO SORIA, 1988, p. 171)
\end{abstract}

A Crónica de Juan /l está inteiramente alinhada à perspectiva aqui descrita. Apresentar o monarca como um pilar indispensável na distribuição de poder e aplicação da justiça parece ser a principal "agenda" do documento, e a importância de Juan II neste aspecto assenta-se na sua legitimidade em conceder senhorios e títulos.

Em primeiro lugar, a narrativa faz questão de sublinhar a obediência dos nobres ao monarca, principalmente seus aliados. Constrói-se um discurso político que coloca nas mãos do rei o poder exclusivo da concessão legítima, tornando-o um intermediário necessário para a prosperidade política dos nobres. A Crónica de Juan II,

\footnotetext{
${ }^{8}$ No original "La nobleza contribuye a prestigiar a un rey, por lo que éste siempre debe preocuparse de estar bien rodeado de grandes señores. Cuanto más nobles tenga un príncipe a su servicio tanto más poderoso podrá ser considerado. Se deberá otorgar a estos nobles cuantas más dignidades y poderes mejor, pues la gloria del soberano será mayor cuanto mayor es el poder de sus grandes." Tradução nossa.
} 


\section{O Poder na Idade Média}

\section{Desterro, legitimidade e distribuição de poder}

portanto, mostra o rei como chave da dinâmica política, na medida em que ele seria o regulador desse processo de remanejamento de senhorios e títulos nobiliárquicos.

Ainda que a crônica possa - e deva - ser questionada, parece difícil divergir da opinião de que o monarca assume papel central no panorama político de 1445 a 1454. O exercício político modelar da coroa como "criadora de nobres" (NIETO SORIA, 1988, p.169), defendido como ideologia de uma parte considerável da aristocracia castelhana, pressupõe a inserção do rei no conflito político, como mediador e regulador. A junção entre modelo e realidade, no caso de Juan II, é, também, uma disputa entre narrativas. Nesse aspecto, as caracterizações da figura do monarca se posicionam entre extremos, que vão do modelar à usurpação do poder régio pelo valido Álvaro de Luna, a depender da intencionalidade do autor. Ambas as interpretações apresentam a coroa - que nesse caso deve ser entendida separadamente da figura do rei - como a verdadeira fonte do poder monárquico. Este aspecto será desenvolvido adiante.

A Crónica de Juan // continua a legitimar a concessão régia, na medida em que é procurada por nobres fora da esfera dos aliados do monarca castelhano. No caso concreto do Almirante de Castela e do Conde de Benavente, ambos procuram reaver suas posses através do perdão régio após a Batalha de Olmedo (PÉREZ DE GUZMÁN, 1779 , p. 500). A concessão do perdão e a escolha do monarca como fonte legítima para a distribuição de justiça são elementos que auxiliam em uma caracterização positiva de Juan II.

A importância do perdão régio na crônica é clara em diversos exemplos, apontando uma estratégia narrativa de valorização da figura do monarca. De acordo com Nieto Soria: 


\title{
O Poder na Idade Média
}

\section{Gabriel Soledade Pereira Lima}

O perdão régio foi uma das expressões mais características, talvez a mais perceptível, do que, no contexto baixomedieval, se entendeu como o exercício do governo pela graça, considerando-se que falar da graça régia era referir-se, em primeira instância, à capacidade do rei para perdoar. Por isso, é compreensível que grande parte da valoração positiva ou negativa que poderia ser feita da ação governamental de um monarca dependesse precisamente do sucesso ou do insucesso que ele havia demonstrado na aplicação do perdão, podendo pecar como injusto, ou pela inclinação excessiva para perdoar, ou o contrário, o que faria dele um rei cruel (NIETO SORIA, 2002, p. 215) .

Em um período marcado por enfrentamentos políticos, a demonstração de magnanimidade a partir do perdão é uma via de fortalecimento e formação de alianças - duradouras ou não - para o monarca, tal como a distribuição de poder.

Outro caminho utilizado para legitimar as concessões régias é a deslegitimação dos opositores de Juan II. No caso específico dos maestrazgos de Santiago e Calatrava, as candidaturas de Rodrigo Manrique e de D. Alonso, filho do rei de Navarra são tratadas em contraposição às candidaturas promovidas pelo monarca. No caso de Rodrigo Manrique, é possível perceber um esforço de deslegitimação na narrativa da crônica:

\begin{abstract}
Estando as coisas nesse estado, o Rei de Aragão escreveu a Rodrigo Manrique fazendo-lhe saber como ele teria concordado e acordado com o Santo Padre Eugenio, que lhe fosse entregue o Mestrado de Santiago, apesar da eleição do Condestável Don Alvaro de Luna, e que dali em diante ele poderia bem se chamar de Mestre de Santiago: e por essa causa Rodrigo Manrique, conhecendo o enfrentamento que começava entre o Rei e o Príncipe, tomou logo para si o título de Mestre, sem esperar as bulas do Santo Padre, nem a vontade do Rei, nem a voz dos Comendadores, e logo escreveu ao Príncipe e a
\end{abstract}

\footnotetext{
${ }^{9}$ No original: "El perdón real fue una de las expresiones más características, acaso la más perceptible, de lo que, en el contexto bajomedieval, se entendió como el ejercicio del gobierno por la gracia, considerándose que hablar de la gracia real era referirse en primera instancia a la capacidad del rey para perdonar, por lo que resulta comprensible que buena parte de la valoración positiva o negativa que se pudiera hacer de la acción gubernativa de un monarca dependiera precisamente del acierto o desacierto que hubiera mostrado en su aplicación, pudiendo pecar de injusto, bien por la excesiva inclinación a perdonar o a lo contrario, lo que le convertiría en un rey cruel." Tradução nossa.
} 


\section{O Poder na Idade Média}

\section{Desterro, legitimidade e distribuição de poder}

Don Juan Pacheco, Marquês de Vilhena, fazendo-Ihes saber como tinha assumido o título de Mestre (PÉREZ DE GUZMÁN, 1779, p. 524) ${ }^{10}$.

No entanto, as reinvindicações pelos maestrazgos - e o reconhecimento da autoridade papal de Eugênio IV e dos comendadores - demonstram como Juan II, apesar de sua importância no plano da concessão de senhorios e títulos, não possuía o monopólio desses instrumentos políticos.

Ao mesmo tempo em que o monarca se apresenta como fonte de legitimidade política, a figura do herdeiro, procurada por nobres "fora das graças" do rei, se apresenta como opção alternativa. O príncipe Enrique se mostra como canal de acesso aos benefícios régios na medida em que trata com nobres desterrados e representantes de Aragão e Navarra, como o Almirante e o conde de Benavente, atuando em prol de seus interesses quando lhe convém. De acordo com Suárez Fernández, o príncipe teria se tornado o novo articulador de uma "oposição nobiliária" ao condestável após a "queda" dos infantes em Castela (SUÁREZ FERNÁNDEZ, 1970, p. 540).

Ainda que a historiografia construa um enfrentamento bipolar - baseado em projetos políticos - entre os partidários do príncipe e do condestável, após 1445, e que em certa medida as crônicas caracterizem algo semelhante, é mais provável que os agentes políticos tenham se aliado ao príncipe por motivos diversos. A partir da

\footnotetext{
${ }^{10}$ No original: "Estando las cosas en este estado, el Rey de Aragón escribió á Rodrigo Manrique haciéndole saber como él tenia concordado, y asentado con el Santo Padre Eugenio, que le proveyese del Maestrazgo de Santiago, no enbargante la elección hecha en el Condestable Don Alvaro de Luna, é que dende adelante se podría bien llamar Maestre de Santiago: é por esta causa Rodrigo Manrique conosciendo la división que se comenzaba entre el Rey, y el el Príncipe, tomó luego los pendones é titulo de Maestre, sin esperar las bulas del Santo Padre, ni la voluntad del Rey, ni la voz de los Comendadores, é luego escribió al Príncipe, é á Don Juan Pacheco Marques de Villena, haciéndoles saber como habia tomado el título de Maestre." Tradução nossa.
} 


\title{
O Poder na Idade Média
}

Gabriel Soledade Pereira Lima

conjuntura criada pela Batalha de Olmedo, porém, parece seguro considerar que alguns desses nobres reconhecem no príncipe uma alternativa de legitimidade. Enrique poderia, como alguém próximo ao monarca e capaz de interferir na dinâmica de distribuição de poder, ou, principalmente, como um "monarca em potencial", acolher o pleito das redes políticas não beneficiadas pelo arranjo político em torno de Juan II.

É possível perceber, portanto, alguns dos valores políticos que a narrativa da crônica busca exaltar na figura régia. Há uma agenda política que atravessa a elaboração dessas narrativas, e o rei, como seus antecessores e sucessores, se utiliza dos mecanismos ali elaborados para legitimar suas decisões e justificar os conflitos dentro e fora do plano da crônica. Afirmar que apenas o monarca, ou seus aliados, podem se beneficiar da construção política tecida pela narrativa seria opor as aspirações da monarquia às da nobreza, no plano dos projetos políticos. Tal perspectiva desconsidera que essa ideia modelar de coroa também pode ser utilizada para legitimar conflitos contra o próprio rei e seus aliados.

Os ideais de "coroa", "bem comum", e proteção do reino são alguns pontos marcantes da construção do discurso legitimador dos nobres que se opõem ao monarca de maneira geral. Nas palavras de Nieto Soria:

\begin{abstract}
A sobrevivência do reino já não se encontra vinculada à persona do rei, mas, para os nobres rebeldes, o reino adquire projeção eterna através da Coroa, à margem da figura real. Assim, através da alusão à Coroa, a crítica ao rei e sua legítima deposição já é possível, uma vez que isso não prejudica necessariamente o reino, cuja expressão máxima não é mais encontrada no rei, mas na Coroa. Assim, o valor ideológico-político do conceito de Coroa Real é extraordinário e fundamental no desenvolvimento das revoltas nobres do século XV. Sem o apelo a tal conceito, a justificação das atitudes nobres contra o rei dificilmente poderia ter sido sustentada (NIETO SORIA, 1988, p. 174) ${ }^{11}$.
\end{abstract}

\footnotetext{
${ }^{11}$ No original: "La supervivencia del reino ya no se encuentra vinculada a la persona del rey, sino que, para
} 


\section{O Poder na Idade Média}

Desterro, legitimidade e distribuição de poder

Portanto, é através de uma construção política própria da aristocracia - de responsabilidade sobre o bem comum da sociedade medieval como um todo - e da dissociação entre a coroa e a figura pessoal do monarca, que o conflito político pode ser legitimado por outro caminho. Esse tipo de construção político-ideológica serve tanto aos interesses do monarca quanto aos interesses da aristocracia, no plano teórico. Mas é no plano da aplicação desta teoria política que ocorrem os conflitos, na medida em que a aristocracia reconhece na figura do monarca, ou em um aliado como é o caso de Álvaro de Luna - uma ameaça ao bem comum do reino. A depender do caso, se estruturará um discurso de salvação que defende o resgate do monarca das mãos de um tirano, como ocorre entre 1445 e 1454 no discurso dos Infantes de Aragão e da nobreza, ou o resgate da coroa das mãos de um monarca incompetente ou tirano (MONSALVO ANTÓN, 2017, p. 110-113).

Na medida em que essa fundamentação política é utilizada por todos os lados, como sustentação teórica nas disputas, é difícil afirmar que o conflito se dá em termos de fortalecimento ou enfraquecimento monárquico. Considerando que a coroa é instrumentalizada para legitimar tanto ações régias quanto nobiliárquicas - a própria ideologia política é fruto de cooperação entre ambas (ESCALONA, 2002, p. 132) - é necessário explicar a situação política de 1445 a 1454 em termos mais contextualizados, em detrimento de uma simples polarização entre nobreza e monarquia. Além de ser difícil, em termos práticos, caracterizar nobreza e monarquia

los nobles sublevados, el reino adquiere proyección eterna a través de la Corona, al margen de la figura real. Así, por tanto, a través de la alusión a la Corona ya es posible la crítica al rey y su legítima deposición, en cuanto que ello no tiene por qué perjudicar necesariamente al reino, cuya expresión máxima ya no se encuentra en el rey, sino en la Corona. Es así que el valor ideológico-político del concepto de Corona Real es extraordinario y fundamental en el desarrollo de las sublevaciones nobiliarias del siglo XV. Sin la apelación a tal concepto, la justificación de las actitudes nobiliarias en contra del rey apenas se habría podido sostener." Tradução nossa. 


\section{O Poder na Idade Média}

Gabriel Soledade Pereira Lima

como antíteses em conflito, visto que todos os "partidos" aqui detalhados eram constituídos por nobres - inclusive o de Juan II e Álvaro de Luna -, em termos ideológico-políticos tal configuração se mostra igualmente improvável.

Dissociar os conflitos políticos após a batalha de Olmedo de etiquetas e partidos homogêneos constitui um passo em uma direção mais complexa. Reconhecer a atuação de diversas redes políticas no território castelhano, as justificativas utilizadas pelos nobres para legitimar o conflito, e o papel do monarca como uma fonte de legitimidade e de ascensão para beneficiados, e de ilegitimidade e descenso para prejudicados pelos “desterros" após Olmedo, parece ser uma boa chave explicativa para o período de rearranjo político de 1445 a 1454.

\section{Reflexões Finais}

A partir do que foi exposto até aqui, parece ser possível compreender o período entre 1445 e 1454 sob uma ótica que excede a "queda de Álvaro de Luna", uma chave interpretativa central do discurso historiográfico. Ao considerar a ampla representação de diferentes grupos políticos ativos que buscam a realização de seus interesses durante o período, pode-se construir uma interpretação menos focada na relação entre valido e monarca e mais preocupada com o conflito político mais amplo em torno dos "grandes", algo que se encontra presente na própria documentação.

Dentro do contexto político apresentado, a figura monárquica se mostra central na medida em que se apresenta como distribuidora de poder legítimo, e, portanto, essencial em uma dinâmica de reestruturação política como foi o período dos desterros após Olmedo. Através da concepção modelar do exercício político régio, compartilhada de maneira geral pela aristocracia, Juan II legitima - ativa ou passivamente (a depender da narrativa) - as posses e títulos obtidos pelos membros 


\section{O Poder na Idade Média}

\section{Desterro, legitimidade e distribuição de poder}

das redes políticas castelhanas durante o período. Mas é necessário dissociar essa prática política de uma aspiração monopolista monárquica. A própria lógica do rei "criador de nobres" presume uma associação direta entre a força do monarca e a distribuição do poder, como detalhado anteriormente. É, portanto, difícil associar à agenda monárquica, pelo menos no plano de sua concepção política, um projeto de aniquilação da aristocracia, na medida em que ambas se complementam e se fortalecem.

Explicar as diversas motivações daqueles conflitos mostra-se uma tarefa mais complexa do que a sua redução a uma polarização entre partido "monarquista" e "nobiliárquico" pressupõe. A pluralidade de redes políticas em ação durante o período, que, inclusive, possuem diversidade social interna, leva à necessidade de encontrar motivações muito mais específicas e contextualizadas. Além da multiplicidade de grupos, a quantidade de narrativas em disputa acerca dos acontecimentos do reinado de Juan II também possibilita vislumbrar os diferentes planos da disputa política. No entanto, todas as crônicas, inclusive as não privilegiadas pela narrativa historiográfica, enfatizam a importância do monarca na dinâmica do poder, pois, manipulada, ou não, sua figura é central como distribuidora de justiça.

Através de uma valorização crítica das fontes, pode-se analisar aspectos políticos que permanecem pouco explorados pela historiografia. Levando em consideração as ideias aqui apresentadas, parece ser possível lançar uma luz diferente, através de um recorte pouco estudado, às interpretações historiográficas consolidadas sobre o século XV castelhano, principalmente por meio da reconstrução da composição das redes que se formaram em torno do poder. 


\section{O Poder na Idade Média}

Gabriel Soledade Pereira Lima

\section{Fontes}

CARRILLO DE HUETE, Pedro. Crónica del Halconero de Juan II. MATA CARRIAZO, Juan de; BELTRÁN, Rafael (eds.). Granada: Universidad de Granada, 2006.

MIGUEL DE FLORES, Josef. Crónica de D. Álvaro de Luna, condestable de los reynos de Castilla y de Leon. Copia digital. Valladolid: Junta de Castilla y Léon. Consejería de Cultura y Turismo, 2009-2010. En Madrid: en la imprenta de D. Antonio de Sancha, 1784.

PALENCIA, Alonso de. Crónica de Enrique IV, intr. de A. Paz y Melia. Madrid: BAE, 1973.

PÉREZ DE GUZMÁN, Fernán. Crónica del señor don Juan, segundo de este nombre em Castilla y en Leon. Valladolid: Junta de Castilla y León. Consejería de Cultura y Turismo, 2009-2010. En Valencia: en la imprenta de Benito Monfort, 1779.

\section{Referências bibliográficas}

CAÑAS GALVEZ, F. de P. “La diplomacia castellana durante el reinado de Juan II: la participación de los letrados de la Cancillería Real en las embajadas regias". Anuario de Estudios Medievales (AEM) 40/2, julho-dezembro de 2010.

COELHO, Maria Filomena. Um universo plural: política e poderes públicos na Idade Média (séc. XII-XIII). In: TORRES FAUAZ, Armando (ed.). La Edad Media en perspectiva latinoamericana. Heredia: Ed. de la Universidad Nacional de Costa Rica, 2018, p. 133150.

ESCALONA, Julio. Los nobles contra su rey. Argumentos y motivaciones de la insubordinación nobiliaria de 1272-1273. Cahiérs d'Études Hispaniques Médiévales, $\mathrm{n}^{\circ} 25,2002$, p.131-162.

GÓMEZ REDONDO, Fernando. El conflicto de ser rey: Juan II, caballero andante.

Anexes des Cahiérs d'Études Hispaniques Médiévales, volume 16, 2004, p.199-218.

MANZANO MORENO, Eduardo. Épocas Medievales. In: FONTANA, J.; VILLARES, R..

Historia de España. Madrid: Critica/Marcial Pons, 2010. 


\section{O Poder na Idade Média}

Desterro, legitimidade e distribuição de poder

MONSALVO ANTÓN, José María. El conflicto "nobleza frente a monarquía" en el contexto de las transformaciones del estado en la Castilla Trastamara. In: FUENTE, José Antonio (Org.). Discurso político y relaciones de poder: Ciudad, nobleza y monarquía en la Baja Idad Media. Madrid: Ed. Dykinson, 2017.

NIETO SORIA, José Manuel. Fundamentos ideológicos del poder real en Castilla (siglos XIII - XVI). Madrid: Ed. Universidad, 1988.

. "Los perdones reales en la confrontación política de la Castilla

Trastámara". En la España Medieval, N² 25, 2002, p.213-266.

PRETEL MARIN, Aurelio. "Algunas acciones militares de Albacete y su comarca en las luchas de los infantes de Aragón (1421-1444)". Al-Basit: Revista de Estudios

Albacetenses, No. 10, 1981.

SUÁREZ FERNÁNDEZ, Luis. Historia de España: Edad Media. Madrid: Editorial Gredos S.A., 1970.

VALDEON BARUQUE, Julio. Reino de Castilla en la Edad Media. In: SUÁREZ FERNÁNDEZ, Luis (Org.). Panoramas de la historia universal. Bilbao: Ediciones Moreton, S.A., 1968. 